\title{
Toward an Archeological Reconstruction of the Xia Dynasty as History: Delineations and Methods
}

\author{
Sun Qingwei 孫慶偉 \\ Professor and Director of the School of Archaeology and Museology, Beijing \\ University, China \\ sunqingwei@pku.edu.cn
}

Translated by Ady Van den Stock

\begin{abstract}
In a broad sense, the term "Xia culture" means the culture of the Xia dynasty [ca. 21001600 BCE ] period. In a narrower sense, however, it refers to the culture of the Xiahou 夏后 clan of the mythical founder Yu 禹. In much of the contemporary research, the question of the primary ethnic affiliation of Xia culture is often overlooked and obscured, thus blurring the distinction between Xia culture in the broad and narrow senses. This has resulted in considerable conceptual and epistemological imprecision. Research on Xia culture can be conducted in two main ways: on the one hand, what has been called "metropolitan conjecture" and, on the other, cultural comparison. Departing from the method of cultural comparison and bringing together temporal, spatial, and cultural elements in our analysis allows us to distinguish a primary central area within the "region of Yu" that coincides with Xia culture in the narrow sense, as reflected in later phases of the Wangwan 王灣 and Meishan 煤山 regional subtypes of Longshan culture [Longshan wenhua 龍山文化], from the later phases of the various archaeological remains found within a secondary and tertiary central area, which can be included in the category of Xia culture in a broad sense. Erlitou 二里頭 culture should be regarded principally as part of Xia culture. As such, the Meishan and Wangwan subtypes of Henan Longshan culture, along with the first to the fourth phases of Erlitou culture, can be seen as making up a consistent Xia culture.
\end{abstract}

\section{Keywords}

Erlitou - evidentiary history - Longshan - Xia dynasty 
It has become clear that the previous ten years of archaeological study and research have failed to yield a scholarly consensus concerning Xia culture [Xia wenhua 夏文化]. Disagreements have steadily increased, to such an extent that some scholars have even begun to question whether the Xia dynasty [ca. 2100-1600 BCE] ever existed at all. There can be little doubt that this situation is essentially the result of methodological flaws haunting research on Xia culture. As early as 1979, Zou Heng 鄒衡 (1927-2005) pointed out:

It has already become rather unlikely that further discoveries of archaeological cultures still await us in the central region at the middle and lower reaches of the Yellow River, described in ancient texts and records as part of the domain of activity of the Xia and Shang peoples. At the same time, however, because the existence of the Xia dynasty is just as much an objective fact as that of the Shang, archaeologically speaking, Xia culture has to be located somewhere within the various stages of the cultural types from this period in history we have already discovered in the region in question. In this sense, the problem is not so much that Xia culture has not yet been discovered but, rather, which methods we should employ to distinguish and identify it. ${ }^{1}$

What Zou is trying to make clear in this passage is that, in researching Xia culture, methodology is more important than discovery. My article focuses on the problem of delineating the boundaries of Xia culture and the methods for researching it, thus critically outlining a path toward the archaeological reconstruction of an evidentiary history of the Xia dynasty.

\section{Archaeological Perspectives on Xia Culture}

"Xia culture" is an archaeological concept. It is related, but not identical to, the idea of the culture of the Xia dynasty period in the broad sense. Contemporary

1 Zou Heng 鄒衡, “Dui dangqian Xia wenhua taolun de yixie kanfa: 1979 nian 5 yue zai Chengdu Zhongguo xianqinshi xuehui chengli dahui shang de fayan gao 對當前夏文化討論的一些 看法一 1979 年 5 月在成都中國先秦史學會成立大會上的發言稿 [Some Remarks on the Current Debate Surrounding Xia Culture: Speech at the Conference for the Establishment of the Association for the Study of Pre-Qin Chinese History]," in Xia Shang Zhou kaoguxue lunwen ji (xuji) 夏商周考古學論文集(續集) [Collected Writings on the Archaeology of the Xia, Shang, and Zhou Dynasties (Supplementary Volume)] (Beijing: Kexue chubanshe, 1998), 24. 
scholars have an ongoing disagreement concerning the notion of Xia culture, related to the methodological problem of how this culture should be researched.

In 1959, before embarking on a survey of the Xiaxu 夏墟 in western Henan Province, Xu Xusheng 徐旭生 (1890-1976) had already developed a clear understanding of the meaning of "Xia culture":

If we want to resolve the problem of Xia culture, we have to emphasize that the term "Xia culture" can refer to two different things. Above, we used this term in a purely temporal sense, as referring to the culture of the Xia dynasty period. However, people formerly believed that China had been unified ever since the time of the Yan emperor and the Yellow emperor. There is no need for us to keep telling the same old tale. It is safe to say that in the Xia period, the end of clan society was already drawing near, while clans still held considerable power, and China remained divided. Therefore, it is quite possible to regard the term "Xia culture" as referring to the culture of one particular clan or tribe. ${ }^{2}$

According to $\mathrm{Xu}$, then, the term "Xia culture" can refer to two different things: to the “Xia clan" [Xia shizu 夏氏族] or “Xia tribe" [Xia buluo 夏部落] collectively or, alternatively, to "the culture of the Xia dynasty period." Consequently, when Xu speaks of "Xia culture," he is speaking about the "culture of the Xiahou clan" [Xiahoushiwenhua 夏后氏文化].

In November 1977, Xia culture again became a prominent topic of interest for archaeology scholars at the Conference on the Excavation of the Gaocheng 告成 Site in Dengfeng 登封, Henan Province, which gave rise to diametrically opposed points of view. ${ }^{3}$ For the sake of arriving at a consensus and facilitating further academic dialogue, Xia Nai 夏鼎 (1910-1985) provided the very first archaeological definition of "Xia culture" in his closing remarks at the conference, describing it as "the culture of the Xia people during the period of the

2 Xu Xusheng 徐旭生, “1959 nian xia yuxi diaocha 'Xiaxu' de chubu baogao 1959 年夏豫西 調查 ‘夏墟” 的初步報告 [Preliminary Report on the 1959 Survey of the 'Ruins of Xia' in Western Henan]," Kaogu 考古, no. 11 (1959): 592.

3 On the importance of this conference, see Sun Qingwei 孫慶偉, “Kaoguxue de chuntian: 1977 nian Henan Dengfeng Gaocheng yizhi fajue xianchanghui de xueshushi jiedu 考古學的 春天: 1977 年河南登封告成遺址發掘現場會的學術史解讀 [The Spring of Archaeology: Interpreting the 1977 Conference at the Excavation of the Gaocheng Site in Dengfeng, Henan Province' from the Standpoint of Intellectual History]," in Zhuiji sandai 追跡三代 [In Search of the Three Dynasties] (Shanghai: Shanghai guji chubanshe, 2015). 
Xia dynasty" ${ }^{\prime 4}$ Xia Nai's definition gained broad acceptance in academic circles and served as a point of departure for future archaeological research into Xia culture. ${ }^{5}$

When Xia Nai talked about the "Xia people" [Xia minzu 夏民族], he was probably referring to what Xu Xusheng had called the "Xia clan" or "Xia tribe" or, in other words, to what contemporary scholars commonly call the "Xia ethnic group" [Xiazu 夏族]. However, strictly speaking, no proof has emerged of the historical existence of a separate "Xia ethnicity" distinguished by ties of consanguinity. The "Basic Annals" [Benji 本紀] of the Records of the Grand Historian [Shiji 史記] say that "after he had named the state Xia, [Yu] adopted the ancestral name [xing 姓] Si 姒,"6 which suffices to make clear that "Xia" was the name for a territorial-political entity, not for a clan with a pure bloodline. If we focus exclusively on blood ties, only those clans during the Xia period whose ancestral name was Si might be seen as corresponding to the term "Xia ethnic group," which would have to include clans listed in the "Basic Annals of the Xia" in the Shi ji, such as Xiahou 夏后, Youhu 有扈, Younan 有男, Zhenxun 勘尋, Tongcheng 形城, Bao 褒, Fei 費, Qi 杞, Zeng 繒, Xing 辛, Ming 冥, and Zhenge 煁戈. This implies that if we want to refrain from approaching the idea of Xia in ethnic terms, we have to conclude that, as some scholars have pointed out, "what is known as the 'Xia ethnic group' primarily refers to the clans that shared the same ancestral name with the Xiahou clan or were related to the latter through intermarriage and together made up the majority of the Xia state."

4 Xia Nai 夏鼎, “Tantan tantao Xia wenhua de jige wenti: zai Dengfeng Gaocheng yizhi fajue xianchanghui bimushi shang de jianghua 談談探討夏文化的幾個問題: 在 '登封告成 遺址發掘現場會' 閉幕式上的講話 [On a Number of Problems Concerning Xia Culture: Speech Delivered at the Closing Ceremony of the Meeting at the Excavation Site of the First Capital of the Xia Dynasty]," Henan wenbo tongxun 河南文博通訊, no. 1 (1978): 32.

5 In recent archaeological studies on the Xia and Shang periods, the dominant opinion remains that "Xia culture refers to the archaeological cultural remains left behind by the Xia ethnic group (or a community dominated by the Xia people) within the territory controlled by the Xia dynasty during the length of its reign" (Gao Wei 高煒 et al., "Yanshi Shangcheng yu Xia Shang wenhua fenjie 偃師商城與夏商文化分界 [Yanshi Shang City and the Division between Xia and Shang Cultures]," Kaogu 考古, no. 10 [1998]: 66).

6 Sima Qian 司馬遷, “Xia benji 夏本紀 [Basic Annals of Xia],” in Shi ji 史記 [Records of the Grand Historian] (Beijing: Zhonghua shuju, 2014), 102.

7 See Shen Changyun 沈長雲 and Zhang Weilian 張渭蓮, Zhongguo gudai guojia qiyuan yu xingcheng yanjiu 中國古代國家起源與形成研究 [An Investigation into the Origin and Formation of the Ancient Chinese State] (Beijing: Renmin chubanshe, 2009), 214; Shen Changyun, "Shuo Xiazu: jianji Xia wenhua yanjiu zhong yixie jidai jiejue de renshi wenti 說夏族: 兼及夏文化研究中一些亟待解決的認識問題 [On the Idea of the Xia Ethnic Group: Including a Discussion of a Number of Epistemological Problems in the Research of Xia Culture That Require an Urgent Solution]," Wen shi zhe 文史哲, no. 3 (2005). 
The real importance of emphasizing the precise importance of the term "Xia people" is making clear who counts as the main subject of research into Xia culture. Does "Xia ethnic group" merely refer to members of the Xiahou clan? Does it have a wider meaning, including all clans with the ancestral name Si? Or could we even include the culture of all the clans in the Xia period? If we look back at the research into Xia culture conducted over the past few decades, we find instances of all these approaches, each laying claim to the term "Xia culture," a situation that is clearly confusing.

Zou Heng was the doyen of twentieth-century Xia and Shang [ca. 160o1046 вСE ] archaeology. At the Conference on the Excavation of the Gaocheng Site in Dengfeng, Henan Province, Zou provided the first systematic account of his views on Xia culture:

A comprehensive investigation into temporal and geographical elements, cultural traits, cultural origins, and phases of social development leads us to the conclusion that the archaeological culture of the Xia dynasty, or Xia culture, was part of Erlitou二里頭 culture (including its two subtypes in their earlier and later periods, which add up to a total of four phases). ${ }^{8}$

Zou would later repeatedly express very similar views, for example, in stating that "the Xia dynasty is a historical category, whereas Xia culture refers to the archaeological culture to which the Xia dynasty belonged"9 ${ }^{\prime \prime}$ or that

given the fact that Xia culture is the culture of the Xia people during the period of the dynasty in question, our primary focus should be on the Xia dynasty itself, that is to say, on a specific state, which obviously raises the question as to what the borders of this state were.... Analyzing the various archaeological cultures already discovered within these boundaries will ultimately allow us to determine which of these cultures might possibly be that of the Xia. ${ }^{10}$

Precisely by departing from this particular understanding of "Xia culture," Zou Heng engaged in a systematic analysis of the relationship between the

8 Zou Heng, “Guanyu tansuo Xia wenhua de tujing 關於探索夏文化的途徑 [Concerning the Path toward an Investigation of Xia Culture]," Henan wenbo tongxun 河南文博通訊, no. 1 (1978): 34 .

9 Zou Heng, "Some Remarks on the Current Debate Surrounding Xia Culture," 27.

10 Zou Heng, “Guanyu tantao Xia wenhua de tiaojian wenti 關於探討夏文化的條件問 題 [On the Problem of the Conditions for Research into Xia Culture]," in Xia Shang Zhou kaoguxue lunwen ji (xuji), 35 . 
domain over which Xia culture was spread and the territory controlled by the Xia dynasty. In his research, the only criterion for the historical remnants left by descendants of the Xiahou clan - other clans with the ancestral name $\mathrm{Si}$, as well as clans with another ancestral name-to qualify as "remnants of Xia culture" or "relics of Xia culture" was that they had to fall roughly within the time span of the Xia dynasty. ${ }^{11}$

However, in other studies, Zou seemed to treat the term "Xia culture" in a more restricted sense as referring to the culture of the Xiahou clan. In one of the texts that laid the foundation for research into Xia culture, "Toward an Analysis of Xia Culture," Zou devoted an entire section, titled "Data and Methods," to the methodological problem of studying Xia culture. He writes:

In the end, is Erlitou the culture of the Shang or the Xia dynasty? In order to resolve this problem, we have to start out from an analysis of Shang culture.... Only if we have successfully identified Shang culture through archaeological study can we distinguish Xia culture.... Any discussion of Shang culture has to begin by resolving the problem of the geographic location of the city of Bo 毫, the first capital of the Shang dynasty, founded by Cheng Tang 成湯. In my view, only after we have determined the location of this city can we further pursue our study of pre-Shang and early Shang culture, which will ultimately enable us to determine the identity of Xia culture. ${ }^{12}$

Zou mentions Xia culture together in one breath with pre-Shang and early Shang culture, while emphasizing the distinction between Xia and Shang cultures. However, the problem is that, chronologically speaking, Xia culture coexisted with pre-Shang culture during a certain period, meaning that, according to Zou's own definitions, pre-Shang culture should count as an integral part of "Xia culture," rather than being a culture in its own right. The only way to resolve this contradiction is to interpret Xia culture as referring to the culture of the Xiahou clan, or to historical remains of the Xia period that are unrelated to the Shang people.

However, the dominant tendency among scholars has been to define "Xia culture" as simply referring to the culture of the period of the Xia dynasty. As

11 See Zou Heng, "Xia wenhua fenbu quyu nei youguan Xiaren chuanshuo de diwang kao 夏文化分佈區域內有關夏人傳說的地望考 [A Topographical Study of Legends surrounding the Xia people within the Domain of Xia Culture]," in Xia Shang Zhou kaoguxue lunwen ji 夏商周考古學論文集 [Collected Writings on the Archaeology of the Xia, Shang, and Zhou Dynasties] (Beijing: Wenwu chubanshe, 1980), 219-52.

12 Zou Heng, “Shilun Xia wenhua 試論夏文化 [Toward an Analysis of Xia Culture]," in Xia Shang Zhou kaoguxue lunwen ji, 105. 
Li Boqian, another important scholar in the field of research into Xia culture, points out:

Erlitou culture, famous for the eponymous archaeological site in the city of Yanshi 偃師 in Henan Province, can be divided into two subtypes: Erlitou proper and Dongxiafeng 東下馮. Zou Heng's identification of Erlitou with Xia culture has currently gained wide acceptance among scholars.... The population of the Erlitou subtype would have consisted primarily of the Xia people, whereas the Dongxiafeng subtype was probably made up of a minority of Xia people who moved to the Dongxiafeng area, along with a majority of local inhabitants who took over Xia culture and were dominated by the Xia court. ${ }^{13}$

Because Li Boqian sees the Erlitou and Dongxiafeng subtypes as corresponding to the culture predominantly produced by the "Xia ethnic group" and "original inhabitants" respectively, he obviously interprets Xia culture as identical to the culture of the Xia dynasty in its entirety.

The various interpretations of Xia culture put forward by scholars such as $\mathrm{Xu}$ Xusheng, Zou Heng, and Li Boqian can be summarized as subscribing to either a narrow or broad understanding of the term "Xia culture." In a narrow sense, Xia culture refers to the culture primarily created by the Xiahou clan, whereas in a broad sense it coincides with the totality of the various cultures of all the different clans that existed during the Xia dynasty. Consequently, our research into Xia culture should begin by clarifying which of these two senses is the basis for how we understand the term.

The Xiahou clan was undoubtedly one of the most distinctive clans in the Xia period. This was the clan to which Yu 禹 belonged and that traced its lineage to the great Si family. In other words, it was the royal clan of the Xia dynasty. As such, the culture of this clan is probably the most representative of the Xia period. In the process of investigating Xia culture, many scholars have attempted to rediscover Xia culture by ascertaining the location of the capital of the Xia dynasty. In the process, the main body of Xia culture is identified as the culture of the Xiahou clan. The latter is presented as the main body because the inhabitants of the capital had very diverse origins, and their culture reflected different influences. In his research on the urban areas of the Three Dynasties, Lin Yun discovered that

13 Li Boqian 李伯謙, Ganwu kaogu 感悟考古 [Understanding Archaeology] (Shanghai: Shanghai guji chubanshe, 2014), 138. 
a crucial factor in the transition from the concentration of the population in urban settlements to the formation of an actual state was precisely the fact that the state became a territorial form of social coexistence instead of one defined by ties of consanguinity. In other words, within the state as a form of social organization, we are no longer dealing with a multiplicity of urban settlements inhabited by different peoples who each claim descent from a particular ancestor but, rather, with a number of cities inhabited by people of different lineages within a given geographic area.... The mixture of various cultural elements from previous historical periods we find in the case of Erlitou culture should not only be understood as being the result of a community that was part of the same lineage absorbing cultural elements from surrounding communities but, rather and above all, as a fusion of the cultures of people from different lineages who inhabited the same area. If it is true that Erlitou culture counts as the historical remains of the "Xia people," this implies that the Xia consisted of different bloodlines. ${ }^{14}$

Obviously, what Lin calls the "Xia people" here is not the same as those people affiliated with the Xiahou clan but can only be understood as referring to the inhabitants of the capital of the Xia dynasty and thus to territorial relations, instead of blood relations. Therefore, instead of identifying Erlitou culture with Xia culture, it would be more accurate to say that Erlitou culture is the culture of the Xia capital. Only when we take into account the fact that the upper social stratum governing the Xia dynasty consisted mainly of descendants of the Xiahou clan can we could go on to argue that the "main body" of the culture of the Xia capital consists of the historical remains of the Xiaohou clan.

In discussing the complexity of ethnic relations in ancient society, Lin Yun writes

Often when we discuss problems like these, we use the term "ethnicity" or "people" [zu 族], which is obviously a highly indeterminate concept. It can be used to refer in a very general sense to the various sorts of more or less unified communities that went by the same name described in ancient texts, the only criterion being that such communities have a smaller scale than do the tribes or tribal alliances in primitive society.

14 Lin Yun 林沄, “Guanyu Zhongguo zaoqi guojia xingshi de jige wenti 關於中國早期國家 形式的幾個問題 [On a Few Problems Concerning the Formation of the Early Chinese State]," in Lin Yun xueshu wenji 林沄學術文集 [Collected Papers of Lin Yun] (Beijing: Zhongguo dabaike quanshu chubanshe, 1998), 98. 
These various communities had huge differences in their historical background and social reality. ${ }^{15}$

In Xia and Shang society, territorial politics had already replaced, at least to some extent, politics based on ties of consanguinity, which makes it hard to determine the domain of activity by one particular clan. In the "Basic Annals of the Xia" in the Shi ji, for example, we read that Xia people with common ancestry, such as the Youhu, Younan, and Zhenxun, "took the name of the state as a family name" [Yongguo weixing 用國為姓], ${ }^{16}$ which means that these tribes were no longer of a single bloodline but part of a feudal state with a population of mixed descent. The point here is that it is difficult to distinguish the cultures of different tribes within the central area of Xia culture from one another. ${ }^{17}$ Hence, in practical terms, we cannot realistically expect to study the distribution of the various clans (tribes) of the Xia period on the basis of the existing divisions between different archaeological cultures. This is why some scholars have opted, instead, to await the excavation of new textual evidence. $^{18}$

Given the many complex problems of culture and ethnicity in the field of archaeology, we have to approach the study of Xia culture from two perspectives at the same time, by taking both the broad and narrow definition of Xia culture into account. In concrete terms, this means, first, we need to pay attention to the importance of the capital of the Xia dynasty. Understanding the

15 Lin Yun, "Kaoguxue wenhua yanjiu de huigu yu zhanwang 考古學文化研究的回顧與 展望 [The Study of Archaeological Cultures: Retrospect and Prospects]," in Lin Yun xueshu wenji, 236.

16 Sima Qian, "Basic Annals of Xia," 109.

17 Bruce Trigger has pointed out that the concept of an archaeological culture is suitable only for small-scale, isolated, and sedentary prehistoric societies. By contrast, for more complex societies with greater cultural diversity as a result of social and economic differentiation, the notion of an archaeological culture is not a suitable analytical tool. See Bruce Trigger 布魯斯·炊格爾, Shijian yu chuantong 時間與傳統 [Time and Traditions], trans. Jiang Zudi 蔣祖棣 and Liu Ying 劉英 (Beijing: Sanlian shudian, 1991), 126.

18 Chang Kwang-chih 張光直 has indicated the importance of textual sources in the study of Xia culture. In his opinion, "in the case of Erlitou culture, the correspondence between its geographical distribution and the location of the capital of the Xia dynasty recorded in legends cannot be entirely coincidental. Only the discovery of a text allowing us to identify Erlitou culture with one of the dynasties or peoples known to us from other written sources will enable us to resolve the problem of the relation between Erlitou culture and the Xia dynasty." However, at the same time, Chang also made the bold claim that "Erlitou culture is Xia culture, and not the culture of the early Shang dynasty" (Gudai Zhongguo de kaoguxue 古代中國考古學 [The Archaeology of Ancient China], trans. Yin Qun 印群 [Beijing: Sanlian shudian, 2013], 376). 
metropolitan culture comes down to understanding Xia culture in the narrow sense, as represented by the Xiahou clan. Second, we need to closely examine the main archaeological sites inhabited by the various clans of the period in question and coming to an understanding of each clan's culture by analyzing the archaeological culture found at these central sites. Third, we need to examine archaeological culture within its proper historical context, thereby establishing the basic features of Xia culture in the broad sense through comparison.

\section{Two Methodologies: Metropolitan Conjecture and Cultural} Comparison

Looking back on the trajectory of research into Xia culture, it is hard not to notice the prominent position taken up by the "method of metropolitan conjecture" [Duyi tuidingfa 都邑推定法]. ${ }^{19}$ We can distinguish between two different approaches to this method: The first is to directly identify an archaeological site as the capital of the Xia dynasty. A typical example of this approach is the identification of the Wangchenggang 王城崗 site in Dengfeng (Henan Province) with Yangcheng 陽城, the capital of the founder Yu, or of the Erlitou site in Yanshi with Zhenxun, the Xia capital during the reign of King Jie 桀. On this basis, one then goes on to infer that the later phase of the Henan Longshan 龍山 culture found in Wangchenggang coincides with early Xia culture, whereas Erlitou culture corresponds to the culture of the late Xia. The second starts by determining the location of Bo, the first capital of the Shang dynasty founded by Tang, to decide upon the location of early Shang culture and then working one's way back from there to reconstruct Xia culture. The subsequent identification of the Shang capital Xibo 西毫 with the Erlitou site and with Yanshi Shang City, which successively took a dominant position in research on Xia and Shang culture, both resulted from this line of reasoning.

The scholarly preference for the "method of metropolitan conjecture," which is not without some merit, can actually be traced back to an unconscious desire to find Xiaxu equivalent to the Yinxu 殷墟, the site of the Shang capital Yin. This also explains why the "method of metropolitan conjecture"

19 Du Jinpeng 杜金鵬 has distinguished three methods for researching Xia culture: comparative verification, the "method of metropolitan conjecture," and the analysis of cultural factors. See Du Jinpeng 杜金鵬, Xia Shang Zhou kaoguxue yanjiu 夏商周考古學 研究 [A Study of the Archaeology of the Xia, Shang, and Zhou Dynasties] (Beijing: Kexue chubanshe, 2007). 
makes sense only within strictly defined conditions and has to be backed up by ironclad proof, such as the discovery of royal tombs or solid textual evidence. If the royal tombs of Xibeigang 西北岡 at the Yinxu site, and along with it the oracle bone script [jiaguwen 甲骨文], had remained undiscovered, many people would still doubt the existence of the Yinxu, and any evidentiary history of the late Shang would be severely compromised.

At first sight, a search for Xia culture grounded in the discovery of historical remains and artifacts, such as the royal tombs of a capital city or textual sources, comes down to a quest for scientifically reliable evidence. What is ignored in the process, however, is the fact that the painstaking search for such evidence already entails a departure from the proper path of archaeological inquiry, which has never taken, and indeed should never take, historical remains and artifacts as its primary research topic. In other words, it is worth asking whether the archaeological study of Xia culture really stands or falls with the discovery of such "ironclad proof." Needless to say, this question should be answered in the negative. As Zou Heng remarked long ago, some people "entertain the notion that the potsherds frequently found at archaeological sites provide us with a sufficient basis to conclusively determine the dating and cultural characteristics of the site in question" precisely "because they have not really understood what modern scientific archaeological study is all about." 20

The popularity of the "method of metropolitan conjecture" has resulted in a situation in which scholars often limit themselves to one particular site or archaeological culture in the hope of finding a single clue that will resolve the entire matter. As a consequence, a flood of articles has appeared that deal almost exclusively with the Erlitou site and Erlitou culture and attempt to solve the problem of Xia culture by studying the characteristic traits of this site or the different phases of this culture. This in turn has led to a proliferation of pointless disagreements and disputes and even raised doubts concerning the existence of the Xia dynasty. ${ }^{21}$ Concerning this phenomenon, Zou Heng made the following astute observations:

20 Zou Heng, "Some Remarks on the Current Debate surrounding Xia Culture," 24.

21 To this day, a small minority of Chinese and foreign scholars continues to doubt the historical existence of the Xia dynasty. A typical line of reasoning is the following: "The earliest records concerning the Xia date from the Zhou dynasty, whereas in the oracle bone inscriptions from the Shang dynasty, which is chronologically closest to the Xia, hardly any mention is made of the Xia. This raises the suspicion that this whole dynasty was a later invention" (Chen Chun 陳淳 and Gong Xin 竟辛, “Erlitou Xia yu Zhongguo zaoqi guojia yanjiu 二里頭、夏與中國早期國家研究 [Erlitou Xia and the Research into the Early Chinese State]," Fudan xuebao [shehui kexue ban] 復旦學報 [社會科學版], no. 
Ever since the end of the 1950s, the majority of research on Xia culture has focused on Erlitou culture. However, in doing so, most scholars have ignored the appropriate approach and methodology put forward by $\mathrm{Xu}$ Xusheng, and no one has bothered to engage in a comparative study of Erlitou culture. Until the beginning of the 1970s, the main approach remained focused on issues of chronology.... All these lacked solid evidence and were thus mostly guesswork that showed little or no genuine insight. In sum, these inquiries were conducted by a small minority of scholars who used it as a means to air their own views in a rather simplistic manner and did not have a great impact at the academic level. ${ }^{22}$

These seemingly heated debates then really amounted to much ado about nothing and were simply an opportunity for scholars to "air their own views in a simplistic manner." Zou's harsh and incisive critique should give us all pause for thought.

$\mathrm{Xu}$ Xusheng's status as a pioneer in the field of Xia culture studies is due not only to the fact that he was the first to embark on a survey of the Xiaxu. More importantly, he was the first scholar to identify what Zou Heng called an "appropriate approach and methodology."23 Throughout the years, Xu consistently expressed his deep dissatisfaction with how the radical movement on "doubting antiquity" neglected the distinction between pure myths and

4 [2004]: 83). In criticizing this line of reasoning, Shen Changyun points out: "A considerable number of foreign scholars still persists in maintaining a fundamentally dismissive attitude when it comes to the existence of the Xia dynasty. They are not acquainted with the historical documents of our country, do not understand the basic approach of Chinese scholars in researching Xia history, and are not even willing to carefully consider whether there might be new data and new points of view in Chinese scholarship on the Xia dynasty. Their denial of the existence of the Xia dynasty has remained grounded in the old arguments put forward by Yang Kuan 楊寬 and Chen Mengjia 陳夢家. What is even worse is that some of these skeptics reduce Chinese scholarship on the Xia to something purely motivated by political interests or moral preconceptions. At this point, the debate loses any semblance of objectivity." (Shen Changyun, "Xiadai shi duzhuan de ma: yu Chen Chun xiansheng shangque 夏代是杜撰的嗎? 與陳淳先生商榷 [Is the Xia Dynasty a Fabrication? A Discussion with Chen Chun]," Hebei shifan daxue xuebao [zhexue shehui kexue ban] 河北師範大學學報[哲學社會科學版], no. 3 [2005]: 90).

Zou Heng, "Xia wenhua yantao de huigu yu zhanwang 夏文化研討的回顧與展望 [Research into Xia Culture: History and Prospects]," Zhongyuan wenwu 中原文物, no. 2 (1990): 5 .

23 On the background and intellectual development of Xu's research into Xia culture, see Sun Qingwei, “Wen Yu wei hewu: Gu Jiegang de Xiashi yanjiu 問禹為何物? 顧頴剛的 夏史研究 [Who or What Was Yu the Great? Gu Jiegang's Research on Xia History], in In Search of the Three Dynasties, 41. 
traditional accounts in a "careless and indiscriminate manner," "made short work of the entire history before the Xia dynasty," and interpreted the "scant historical accounts of the Xia dynasty" as forgeries from the Eastern Han period (25-220), thus "turning the long historical period predating the Yinxu into a blank page." ${ }^{24}$ This is the reason he engaged in a systematic and comprehensive reflection on the proper methodology for researching Xia culture.

Long before starting his search for the Xiaxu in 1959, Xu had decided upon a methodological procedure:

If we can be sure that China was far from unified at that time, it follows that the sphere of activity of the Xia clan or tribe must have been relatively limited. As such, we can proceed by investigating the commonalities or similarities peculiar to Xia culture within its own boundaries and then going on to determine whether we can identify corresponding cultural differences in areas at a relative distance from the central Xia areas. Through a comparative study of cultural differences, we will gradually be able to identify the specificities of the culture of the Xia clan or tribe. ${ }^{25}$

Clearly then, Xu's methodological focus in researching Xia culture was "cultural difference," precisely that of engaging in a comparison of the archaeological culture of the Xiaxu with that of "relatively remote places" and bringing out the peculiarities of Xia culture through comparison. This is why the reconstruction of the Xia capital had little impact on his fundamental understanding of Xia culture.

The sort of research methodology adhered to by Xu Xusheng can be called that of "cultural comparison." For this methodology to be successful, two basic conditions have to be in place: first, a correct identification of the Xiaxu, and, second, an adequate understanding of these ruins as well as of the archaeological cultures outside this area. These two tasks were undertaken by Xu Xusheng and Zou Heng respectively.

In providing a definition for the $\mathrm{Xiaxu}, \mathrm{Xu}$ argued:

If we want to determine the sphere of activity of the Xia clan or tribe, we have to begin our search in legendary accounts handed down from antiquity, that is, by looking at the data contained in textual sources....

24 Xu Xusheng, Zhongguo gushi de chuanshuo shidai 中國古史的傳說時代 The Legendary Era of Ancient Chinese History (Guilin: Guangxi shifan daxue xuebao, 2003), 30.

25 Xu Xusheng, "Preliminary Report on the 1959 Survey of the 'Ruins of Xia," 593. 
To make a rough estimate: there are around 80 passages in pre-Qin texts that provide us with historical information related to the Xia dynasty and also mention specific place names, of which about seventy have been preserved. Apart from this, in texts from the Western Han period [206$25 \mathrm{BCE}]$, there are approximately thirty such passages. However, these are mostly reformulations of pre-Qin accounts, and very few of the place names mentioned fall outside the geographic domain of the immediate pre-Qin period.... The recorded passages that are of the greatest interest to us because they mention the capital of the Xiahou clan number no more than thirty, most of which can be found in the Zuozhuan 左傳 [Commentary of Zuo], Guoyu 國語 [Discourses of the States], and Guben zhushujinian 古本竹書紀年 [Ancient Bamboo Annals].... After a comparative study of the few remaining historical fragments, we can surmise that the following two areas are of particular interest to us: first, the Luoyang 洛陽 plain and its surrounding areas in central Henan, particularly the regions of Dengfeng and Yuxian 禹縣 at the upper reaches of the Ying 穎 river; and, second, the region around the lower reaches of the Fen 汾 river in southwest Shanxi Province (roughly south of Mount Huo 霍山). ${ }^{26}$

Although Xu Xusheng managed to correctly delineate the area of the Xiaxu, the utter lack of precise knowledge concerning the archaeological cultures of the Xiaxu and its surrounding areas at the time prevented him from adequately meeting the second condition for comparative research described above, which would have enabled him to come to a concrete and correct archaeological assessment of Xia culture. Afterward, when Zou Heng assessed the state of the field that confronted him, he took it upon himself to carry Xu's research further and make a decisive contribution to the study of Xia culture.

In describing the background of his own research, Zou writes:

The reason that so little progress had been made in the field of research into Xia culture was that the objective preconditions for engaging in comprehensive comparative research had yet to mature. This mainly expressed itself in the very uneven development of archaeology and in the small number of new archaeological discoveries during the entire 1960s. The available archaeological data had not been sufficiently explored and existing research did not go far enough. Only with the arrival of the 1970 did this situation begin to gradually change. First, advances were made in the archaeological study of the western Henan region. Although

26 Xu Xusheng, "Preliminary Report on the 1959 Survey of the 'Ruins of Xia', 593. 
Zhengzhou Shang city, for example, had already been discovered in the 1950s and a considerable amount of work had gone into studying this site during the 1960s, a number of crucial problems remained unresolved. It was only because of the further research done in the 1970s that the site was definitively confirmed as a Shang dynasty city. Another example is that of the Yanshi Erlitou site. The remains of Palace 1 had already been discovered long ago, but the excavation of the site was only completed in the 1970s, at which point a new chronological division of Erlitou culture was also introduced. Second, the Dongxiafeng and Taosi 陶寺 sites were discovered in western Shanxi Province. Third, on a broader national level, archaeological work in eastern China was now in full swing, so that the features and chronologies of the various cultures found there had been more or less determined. These conditions made it possible not only to continue the work of establishing chronological divisions but also to initiate research into a typology of cultures. ${ }^{27}$

We can also discern the following two steps in Zou Heng's research: first, determining the geographic reach of the Xiaxu and, then, going on to "tease out" Xia culture by comparing the cultures inside and outside this area.

Zou's "Topographical Study of Legends Surrounding the Xia people within the Domain of Xia Culture" contains the research he devoted to defining the reach of the Xiaxu. ${ }^{28}$ As far as this problem was concerned, he came to roughly the same conclusions as $\mathrm{Xu}$ Xusheng and proposed that the Xia people were primarily active in the following three areas:

First, western Henan, possibly extending to eastern Shaanxi and western Hubei Province, or even stretching as far parts of eastern Sichuan and other regions. Second, the southwest Shanxi area, whose influence might have extended to northern Shanxi or even Inner Mongolia. Third, eastern Henan, perhaps stretching to parts of western Anhui and eastern Hubei, a region whose influence may have extended to the lower reaches of the Yangtze River. ${ }^{29}$

However, given the enormous cultural diversity within the area outlined above, the crucial question became which cultures to single out for comparison. Zou's

\footnotetext{
27 Zou Heng, "Research into Xia Culture: History and Prospects," 5.

28 Zou Heng, "Xia wenhua fenbu quyu nei youguan Xiaren chuanshuo de diwang kao," 219-52.

29 Zou Heng, "Toward an Analysis of Xia Culture," 138.
} 
foremost contribution consists in having completed a task left unfinished by $\mathrm{Xu}$ Xusheng: providing a comparative study of the archaeological cultures within and outside the area of the Xiaxu, whose main results are concentrated in the two texts "Toward an Analysis of Xia Culture" and "A Preliminary Investigation into the Neighboring Cultures of the Northern Regions during the Xia and Shang Periods." ${ }^{30}$ Zou assessed the significance of these two studies as follows:

"Toward an Analysis of Xia Culture" provides a general account of the chronology and different periods of Shang culture by bringing together previous studies of the issues in question, while also putting forward a new periodization of early Shang culture. As such, it offers an overall clarification of the origin and development of Shang culture. The chronology and periodization of Xia culture is slightly less complicated than that of Shang culture. This work takes into account the results of all previous studies and puts forward a comparative analysis of the relations between the various periods of Xia and Shang cultures.... "A Preliminary Investigation into the Neighboring Cultures of the Northern Regions" is closely related to "Toward an Analysis of Xia Culture" and can be seen

3o Although the major importance of the first text is generally acknowledged among scholars, the second has generally failed to attract much interest. According to Chang Huaiying 常懷穎, a young scholar who has devoted extensive study to Xia and Shang cultures in this region, "the most emblematic study into Xia and Shang culture in Hebei Province beginning in this period [i.e., 1977-1997] is Zou Heng's 'A Preliminary Investigation into the Neighboring Cultures of the Northern Regions during the Xia and Shang Periods.' In this text, Zou makes use of a limited amount of data to divide the archaeological cultures of the Xia and Shang periods in the area of Hebei Province into Xiajiadian 夏家店 culture, pre-Shang culture, and Guangshe 光社 culture and retraces these cultures to three subtypes of the Longshan culture in Hebei: Leishan 雷山, Jiangou 澗溝, and Xutan 許坦. After giving a detailed analysis of the chronological and geographic distribution of these three archaeological cultures, Zou provides a tentative discussion of their corresponding ethnic affiliations by connecting his data to textual sources.... After the appearance of Zou's study, not a single scholar tried to produce a survey of the Hebei region during this period on the same scale and with a similarly comprehensive orientation, although specialists of different areas during the Xia and Shang periods have provided us with more specific separate studies." (Chang Huaiying 常懷穎, “Xia Shang shiqi gu Jizhou zhiyu de kaoguxue yanjiu 夏商時期古冀州之域的考古學研究 [An Archaeological Investigation into the Region of Hebei Province during the Xia and Shang Periods]," PhD diss., Beijing University, 2010, 31.) See also Zou Heng, "Toward an Analysis of Xia Culture," 95-182; Zou Heng, "Guanyu Xia Shang shiqi beifang diqu zhu linjing wenhua de chubu tantao 關於夏商時期北方地區諸鄰境文化的初步探討 [A Preliminary Investigation into the Neighboring Cultures of the Northern Regions during the Xia and Shang Periods]," in Xia Shang Zhou kaoguxue lunwen ji, 253-94. 
as a supplement to this text. Previously, most historians and archaeologists had located the origins of the Shang people in eastern China. By contrast, on the basis of a large amount of reliable archaeological data, this text proves beyond all doubt that the Shang originated neither in the coastal region nor in the Northeast.... The text concludes that the historical struggle between the Xia and Shang peoples was simply a continuation of the competition between the Gonggong 共工 people inhabiting the region of Hebei and theXia people who mainly occupied the Henan region. ${ }^{31}$

In sum, through a systematic study of the archaeological cultures from the Xia and Shang periods in the three regions mentioned above, particularly by distinguishing and analyzing the marked differences between the Erlitou cultural system in Henan and the pre-Shang cultural system in Hebei, Zou reached the conclusion that Xia culture coincides with the first to the fourth phases of Erlitou culture. As such, he provided the first complete archaeological description of Xia culture. With this, Zou Heng finally brought the research system and paradigm first put forward by Xu Xusheng to completion after more than twenty years of scholarly effort. Contemporary research into Xia culture continues to operate within the academic framework set by $\mathrm{Xu}$ and Zou and has not shown any signs of breaking out of it. ${ }^{32}$

\section{From Longshan to Erlitou Culture: Deepening the Method of Cultural Comparison}

In the autumn of 1930, the Institute of History and Philology of Academia Sinica discovered the archaeological site of Chengziya 城子崖 near the town

31 Zou Heng, Collected Writings on the Archaeology of the Xia, Shang, and Zhou Dynasties, ii-iii.

32 Among studies in the field of Xia culture published in the wake of Xu and Zou, Zheng Jiexiang's 鄭傑祥 Xiashi chutan deserves special mention for its systematic approach. This book is divided into two parts: the first, "A Brief Survey of the History of the Xia Dynasty," provides a "brief study of the origins of the Xia people as well as their area of activity and the political rise and downfall of the Xia dynasty on the basis of textual records." Zheng Jiexiang 鄭傑祥, Xiashi chutan 夏史初探 [A Preliminary Study of Xia History] (Zhengzhou: Zhongzhou guji chubanshe, 1988), 4. The second part, "An Exploration of Xia Culture," is an analysis of the Longshan and Erlitou cultures in Henan. Its main focus argues that the Zhengzhou Shang city site was the first capital of the Shang dynasty to prove that Erlitou culture is identical to Xia culture. Both the formal layout and the content of this book faithfully follow the example set by Xu and Zou. 
of Longshan in Licheng 歷城 District, Shandong Province, and identified a prehistoric culture characterized by its use of black pottery: Longshan culture. ${ }^{33}$ As soon as signs of this culture were discovered, it was paired with Yangshao 仰韶 culture and its typical painted pottery as archaeological evidence of the thesis that "the Yi 夷 people came from the east; the Xia from the West." ${ }^{34}$

For a relatively long time afterward, Longshan culture remained synonymous with black pottery culture, such that all sites where black pottery was unearthed were associated with Longshan culture. Moreover, the introduction of terms such as Shandong Longshan culture, Henan Longshan culture, Shaanxi Longshan culture, and Hubei Longshan culture gradually made "Longshan culture" an extremely indeterminate concept, denoting an aggregate of archaeological cultures with their own particularities, cultural traditions, and geographic distribution. ${ }^{35}$ In light of this, in the beginning of the 1980 s, Yan Wenming drew attention to the necessity of distinguishing between Longshan culture in different regions and giving each regional culture a suitable name. At the same time, Yan proposed calling the entire period represented by these different cultures the "Longshan era," a suggestion that resonated with many scholars in the field. ${ }^{36}$

On the basis of results from radiocarbon dating available at the time, Yan proposed that the various archaeological cultures in the Longshan era be dated between the twenty-sixth and twenty-first century вСЕ, which is earlier than the chronological range for the Xia dynasty in textual records and corresponds more or less to the era of the sage-kings Yao 堯 and Shun 舜 in ancient legends. ${ }^{37}$ However, more recent data has made it clear that the Longshan era falls between 2300 and $1800 \mathrm{BCE}$, which mostly overlaps with the traditional

33 See Li Ji 李濟 et al., Chengziya: Shandong licheng xian longshanzhen zhi heitao wenhua yizhi 城子崖: 山東歷城縣龍山鎮之黑陶文化遺址 [Chengziya: Relics from the Black Pottery Culture Found in the Town of Longshan in Licheng County, Shandong Province] (Nanjing: Zhongyang yanjiuyuan lishi yuyan yanjiusuo, 1934).

34 See Sun Qingwei, "Youxin haishi wuyi: Li Ji Fenhe liuyu diaocha yu Xia wenhua tansuo 有心還是無意: 李濟汾河流域調查與夏文化探索 [Purposefully or Unintentionally: Li Ji's Survey of the Fen Valley and Research into Xia Culture]," in In Search of the Three Dynasties, 77-102.

35 For an overview of the development of archaeological knowledge concerning Longshan culture, see Liu Li 劉莉, Zhongguo xinshiqi shidai: maixiang zaoqi guojia zhilu 中國新石 器時代: 邁向早期國家之路 [The Chinese Neolithic: Trajectories to Early States], trans. Chen Xingcan 陳星燦 et al. (Beijing: Wenwu chubanshe, 2007).

36 See Yan Wenming 嚴文明, “Longshan wenhua yu Longshan shidai 龍山文化與龍山時 代 [Longshan Culture and the Longshan Period]," Wenwu 文物, no. 6 (1981).

37 Yan Wenming obviously meant this in a very loose and general sense, since if the Longshan era is dated from the twenty-sixth to the twenty-first centuries BCE, it cannot be encompassed by the era of Yao and Shun alone. 
chronology of the Xia dynasty. ${ }^{38}$ This makes it clear that, regardless of which dates we adopt, some form of overlap is bound to remain between the Longshan era and the reign of the Xia dynasty, meaning that early Xia culture has to be identified and analyzed within the context of the various archaeological cultures in the Longshan era.

If we look at the geographic distribution of urban settlements in the Xia dynasty, it appears that the Xiahou clan was mostly active in western Henan, in the region around the upper reaches of the Ru 汝 and Ying 穎 Rivers and in the region around the Yiluo 伊洛 River. However, at some point, its influence extended to parts of eastern Henan, northern Henan, and western Shandong. If we also take into account the domain of activity of the clans with which the Xiahou shared the same ancestral name or that of other clans to which they were closely related, the sphere of influence of the Xia dynasty can be further broadened to parts of the westernmost region of Henan, southwestern Shanxi, and northern Anhui. The archaeological cultures in the Longshan era found in these regions are listed in Table 1.

I have expanded the scope of my inquiry to Longshan remains found in the entire "region of Yu." I do this in the hope of making our search broad enough to find the missing pieces of the puzzle of Xia culture through a comparative investigation over a long period in a broad region. In assessing the identity of the various archaeological cultures in question, I have consistently opted for a statistical approach, first identifying and analyzing the makeup of the central artifacts at each representative archaeological site and then proceeding to determine the cultural identity of the historical remains on this basis. An interpretation of the various archaeological cultures listed in Table 1 yields the following results.

First, subtypes of Longshan culture, such as Meishan 煤山, Wangwan 王灣, Zaolütai 造律台, Hougang 後岡, and Sanliqiao 三里橋 [see Table 1], make up a relatively consistent culture. The most widely spread and commonly found artifacts in this sphere are deep-bellied jars [jiasha shenfu guan 夾砂深腹罐] with a gritty texture, which were used as cooking vessels. In this sense, we can speak of a "jar cultural sphere." Other commonly found objects include cups and bowls (or covers for bowls) used for eating and drinking, and containers such as double-bellied basins [shuang fu pen 雙腹盆] and high-necked jars

38 “Zhonghua wenming tanyuan” gongcheng xiangmu zhixing zhuanjiazu “中華文明探源” 工程項目執行專家組 [Specialized Research Group for the Project “Tracing the Origins of Chinese Civilization"], "Zhonghua wenming tanyuan" gongcheng chengguo jicui (neibu ziliao) “中華文明探源” 工程成果集萃(內部資料) [Compendium of Research Results from the Project "Tracing the Origins of Chinese Civilization," internal document], 2016, 5 . 


\begin{tabular}{|c|c|c|}
\hline Region & & Historical remains \\
\hline \multirow[t]{2}{*}{ Primary central region } & $\begin{array}{l}\text { Upper reaches of the Ru and } \\
\text { Ying Rivers }\end{array}$ & Meishan type \\
\hline & Region of the Yiluo River & Wangwan type \\
\hline \multirow[t]{2}{*}{ Secondary central region } & $\begin{array}{l}\text { Eastern Henan, } \\
\text { western Shandong }\end{array}$ & Zaolütai type \\
\hline & $\begin{array}{l}\text { Northern Henan, } \\
\text { southern Hebei }\end{array}$ & Hougang type \\
\hline \multirow[t]{4}{*}{ Tertiary central region } & Westernmost Henan & Sanliqiao type \\
\hline & $\begin{array}{l}\text { Southwestern Shanxi } \\
\text { (Eastern part) }\end{array}$ & Sanliqiao type \\
\hline & $\begin{array}{l}\text { Southwestern Shanxi } \\
\text { (Western part) }\end{array}$ & Taosi culture \\
\hline & Northern Anhui & Huajiasi type \\
\hline
\end{tabular}

[gaoling weng/guan 高領鹤/罐]. Contemporary scholars usually refer to this highly consistent cultural sphere as Henan Longshan culture. The geographic distribution of this culture basically corresponds to the central area described in the available textual evidence as falling under the control of the Xia dynasty, and its absolute chronology mostly matches the chronology of the Xia dynasty. This spatial and temporal correspondence should not be interpreted as mere coincidences but understood as implying that Henan Longshan culture, particularly in its later phase, represents the physical remains of the Xia dynasty.

Second, the cultural similarities among the three central areas described above progressively decrease from one area to the next. This means that the Wangwan and Meishan types in the primary central area are the most closely related, the main difference being the discrepancy between the number of ding 鼎 vessels found in their respective regions. By contrast, the differences between the Zaolütai and Hougang types and the Wangwan and Meishan types are much more marked, as is evidenced by the higher number of yan 戲 vessels, basins with a flat base, and a greater preponderance of elements from Shandong Longshan culture. That being said, the overwhelming dominance of deep-bellied jars with a gritty texture makes it abundantly clear that this area was part of "jar culture." The three types of historical remains in the tertiary central area can further be divided into two levels. At the first level, whereas the Sanliqiao type is part of the Henan Longshan cultural system, it is a highly 
distinctive form of the latter and shows much clearer differences than those found between Zaolütai and Hougang, on the one hand, and Wangwan and Meishan, on the other, with many $g e$ 鬲 tripods, single-eared jars, pottery decorated with cord marks [shengwen 繩紋], and only a small number of jars with a gritty texture among the cooking vessels. As such, the identity of Sanliqiao as part of "jar culture" is far from self-evident. The second level in this tertiary central area consists of Taosi culture and Huajiasi 花家寺 culture, which both represent independent archaeological cultures and only show signs of mutual contact and influence with Henan Longshan culture. Although the Huajiasi type seems to display slightly more similarities with cultural elements from Henan Longshan culture than with Taosi culture (with the latter showing signs of having actively rejected Henan Longshan culture), it is actually the beihu 背菛 pots distinctive of Taosi culture that can be found in Wangwan and Meishan archaeological sites. This means that Taosi culture and the Huajiasi type were completely independent cultural communities that existed side by side with "jar culture."

Third, if we look at the distribution of ethnic groups, we see that the primary central area identified above was mostly the home of the Xiahou clan and the Zhenxun and Fei clans with which the Xiahou shared a common ancestral name. In addition, we find members of the Luo 洛 tribe, whose ancestry is uncertain, and a small portion of “non-native" peoples, such as the Houyi 后羿 and Hanzhuo 寒浞. The ethnic composition of the secondary central area is the most heterogeneous, with a clear presence of descendants of the "eight surnames of Zhurong 祝融," the Youyu 有虞 clan, the Gaoyao 賭陶 clan whose ancestral name was Yan 偃, the Boyi 伯益 clan with the ancestral name Ying 嬴, and ethnic groups from eastern China such as the Qionghan 窮寒 clan. Among the ethnic groups already identified in northern Anhui in the tertiary central area is the famous Tushan 塗山 clan, which was most part of the Huayi 淮夷 cultural system. In the westernmost region of Henan, we find the Tongcheng clan with the ancestral name Si, while the basin of the Linfen 臨汾 and Yuncheng 運城 Rivers was the home base of the Taotang 陶唐 clan.

Combining the information we have concerning the distribution of ethnic groups with our knowledge of the extent of contact between the archaeological cultures in each area allows us to draw a number of conclusions, which are rich in implications. The Wangwan and Meishan types are highly uniform. This area was mostly inhabited by members of clans with the ancestral name $\mathrm{Si}$, such as the Xiahou and Zhenxun clans, and it is quite normal for members of clans with the same ancestor to share a similar material culture. The correspondence between the Zaolütai and Hougang types in the secondary central area, on the one hand, and the Wangwan and Meishan types in the 
primary central area, on the other, in all likelihood are the concrete reflections of an alliance between the Yi and Xia peoples (including the descendants of the eight tribes of Zhurong) mentioned above. Although certain portions of eastern Yi clans, best represented by the descendants of Gaoyao and Boyi, had been Sinicized [huaxiahua 華夏化], and their mode of existence did not differ from that of clans with the ancestral name Si such as the Xiahou, and since the jiyi 雞彝 (ceramic long-stemmed cups known as gui 鬶), which were crucial implements in the "Xia rites," were originally produced in eastern China, it is clear that Xia culture contained elements typical of eastern China. ${ }^{39}$ We could even say that what is known as Xia culture is largely the product of the fusion of the Yi and Xia peoples, which means that Xia culture has no such thing as a "pure lineage." In southern Shanxi in the tertiary central area, the culture of the Taotang clan as exemplified by Taosi culture continued to offer considerable resistance after the founding of the Xia dynasty and retained control over large parts of the Linfen and Yuncheng basin. Only the Yuanqu 垣曲 basin and the area around Xia county might have belonged to an area where Xia culture was also widespread. In northern Anhui, because of the strong influence of an existing culture-Dawenkou 大汶口 culture-and the overpowering "burden of history" this placed upon the region, Xia culture as an external influence never managed to fundamentally alter the local cultural tradition. This gave rise to the formation of the Huajiasi type, as a mixture of elements from Shandong Longshan culture, Henan Longshan culture, and the local culture. Although clans bearing the ancestral name Si were distributed in the westernmost region of Henan, the Sanliqiao type found in this region is clearly distinct in its cultural traits from the Wangwan and Meishan types, which shows the complex nature of the relationship between archaeological culture and ethnic affiliation. As such, it was entirely possible for archaeological culture to transcend ties of consanguinity. The cultures of clans with the same ancestral name were not necessarily the same, nor were cultures of clans with different ancestors necessarily different. In the distinction between Hua and Yi people (or Chinese and "barbarian"), the fundamental criterion is culture, not blood ties.

To summarize the arguments presented above, in the later phase of the Longshan period, the Wangwan and Meishan types in the primary central area can be understood as Xia culture in the narrow sense - the culture mainly produced by the Xiahou clan. Together with the Zaolütai and Hougang types in the secondary central area, they constitute Xia culture in a broad sense- that is, the culture of the Xia dynasty as grounded in an alliance of different clans. 
In the tertiary central area, the situation is even more complex. Although the main part of southern Shanxi and certain regions of northern Anhui were to varying degrees culturally connected to the Wangwan and Meishan types, we cannot include them in the Henan Longshan cultural system. Rather, these areas should be seen as independent cultural spheres. In terms of their political relations, however, the Xiahou clan, on the one hand, and the Taotang clan of southern Shanxi as well as the Tushan clan from northern Anhui, on the other, were very closely connected. As such, the Taotang clan (including the Yulong 禦龍 clan descended from them) and the Tushan clan were both integral parts of the Xia dynasty. Therefore, their historical remains should also be included as part of Xia culture in the broad sense.

\section{Works Cited}

Chang Huaiying 常懷穎. "Xia Shang shiqi gu Jizhou zhiyu de kaoguxue yanjiu 夏商 時期古冀州之域的考古學研究 [An Archaeological Investigation into the Region of Hebei Province during the Xia and Shang Periods]." PhD diss., Beijing University, 2010.

Chang Kwang-chih 張光直. Gudai Zhongguo de kaoguxue 古代中國的考古學 [The Archaeology of Ancient China]. Translated by Yin Qun 印群. Beijing: Sanlian shudian, 2013.

Chen Chun 陳淳 and Gong Xin 襲辛. “Erlitou Xia yu Zhongguo zaoqi guojia yanjiu 二里頭、夏與中國早期國家研究 [Erlitou Xia and the Research into the Early Chinese State]." Fudan xuebao (shehui kexueban) 復旦學報 (社會科學版), no. 4 (2004): 82-91.

Du Jinpeng 杜金鵬. Xia Shang Zhou kaoguxue yanjiu 夏商周考古學研究 [A Study of the Archaeology of the Xia, Shang, and Zhou Dynasties]. Beijing: Kexue chubanshe, 2007. Gao Wei 高煒 et al. “Yanshi Shangcheng yu Xia Shang wenhua fenjie 僧師商城與夏商 文化分界 [Yanshi Shang City and the Division between Xia and Shang Cultures]." Kaogu 考古, no. 10 (1998): 66-79.

Li Boqian 李伯謙. Ganwu kaogu 感悟考古 [Understanding Archaeology]. Shanghai: Shanghai guji chubanshe, 2014.

Li Ji 李濟 et al. Chengziya: Shandong licheng xian longshanzhen zhi heitao wenhua yizhi 城子崖: 山東歷城縣龍山鎮之黑陶文化遺址 [Chengziya: Relics from the Black Pottery Culture Found in the Town of Longshan in Licheng County, Shandong Province]. Nanjing: Zhongyang yanjiuyuan lishi yuyan yanjiusuo, 1934.

Lin Yun 林沄. Lin Yun xueshu wenji 林沄學術文集 [Collected Papers of Lin Yun]. Beijing: Zhongguo dabaikequanshu chubanshe, 1998. 
Liu Li 劉莉. Zhongguo xinshiqi shidai: maixiang zaoqi guojia zhilu 中國新石器時代: 邁 向早期國家之路 [The Chinese Neolithic: Trajectories to Early States]. Translated by Chen Xingcan 陳星燦 et al. Beijing: Wenwu chubanshe, 2007.

Shen Changyun 沈長雲. “Shuo 'Xiazu' : jianji Xia wenhua yanjiu zhong yixie jidai jiejue de renshi wenti 說 ‘夏族” : 兼及夏文化研究中一些亟待解決的認識問題 [On the Idea of the 'Xia People': Including a Discussion of a Number of Epistemological Problems in the Research of Xia Culture That Require an Urgent Solution]." Wen shi zhe 文史哲, no. 3 (2005): 61-68.

Shen Changyun 沈長雲. “Xiadai shi duzhuan de ma: yu Chen Chun xiansheng shangque 夏代是杜撰的嗎：與陳淳先生商榷 [Is the Xia Dynasty a Fabrication? A Discussion with Chen Chun]." Hebei shifan daxue xuebao (zhexue shehui kexue ban) 河北師範 大學學報 (哲學社會科學版), no. 3 (2005): 89-96.

Shen Changyun 沈長雲 and Zhang Weilian 張渭蓮. Zhongguo gudai guojia qiyuan yu xingcheng yanjiu 中國古代國家起源與形成研究 [An Investigation into the Origin and Formation of the Ancient Chinese State]. Beijing: Renmin chubanshe, 2009.

Sima Qian 司馬遷. Shi ji 史記 [Records of the Grand Historian]. Beijing: Zhonghua shuju, 2014.

Sun Qingwei 孫慶偉. Zhuiji sandai 追跡三代 [In Search of the Three Dynasties]. Shanghai: Shanghai guji chubanshe, 2015.

Trigger, Bruce 布魯斯 - 炊格爾. Shijianyu chuantong 時間與傳統 [Time and Traditions]. Translated by Jiang Zudi 蔣祖棣 and Liu Ying 劉英. Beijing: Sanlian shudian, 1991.

Xia Nai 夏鼎. “Tantan tantao Xia wenhua de jige wenti: zai 'Dengfeng Gaocheng yizhi fajue xianchanghui' bimushi shang de jianghua 談談探討夏文化的幾個問 題：在 ‘登封告成遺址發掘現場會” 閉幕式上的講話 [On a Number of Problems Concerning Xia Culture: Speech Delivered at the Closing Ceremony of the Conference at the Excavation of the Gaocheng Site in Dengfeng, Henan Province]." Henan wenbo tongxun 河南文博通訊, no. 1 (1978): 32-33.

Xu Xusheng 徐旭生. “1959 nian xia yuxi diaocha 'Xiaxu' de chubu baogao 1959 年夏豫 西調查 ‘夏墟” 的初步報告 [Preliminary Report on the 1959 Survey of the 'Ruins of Xia' in Western Henan].” Kaogu 考古, no. 11 (1959): 592-6oo.

Xu Xusheng 徐旭生. Zhongguo gushi de chuanshuo shidai 中國古史的傳說時代 The Legendary of Era of Ancient Chinese History]. Guilin: Guangxi shifan daxue xuebao, 2014.

Yan Wenming 嚴文明. “Longshan wenhua yu Longshan shidai 龍山文化與龍山時代 [Longshan Culture and the Longshan Period]." Wenwu 文物, no. 6 (1981): 41-48.

Zheng Jiexiang 鄭傑祥. Xiashi chutan 夏史初探 [A Preliminary Inquiry into Xia History]. Zhengzhou: Zhongzhou guji chubanshe, 1988.

Zhongguo xianqin shi xuehui 中國先秦史學會 [Chinese Association for the Study of Pre-Qin History], ed. Xiashi luncong 夏史論叢 [Collected Essays on the History of the Xia Dynasty]. Ji'nan: Qilu shushe, 1985. 
“Zhonghua wenming tanyuan” gongcheng xiangmu zhixing zhuanjiazu “中華文明探源” 工程項目執行專家組 [Specialized Research Group for the Project “Tracing the Origins of Chinese Civilization”]. "Zhonghua wenming tanyuan” gongcheng chengguo jicui (neibu ziliao) “中華文明探源”工程成果集萃（內部資料）[Compendium of Research Results from the Project "Tracing the Origins of Chinese Civilization," internal document], 2016.

Zou Heng 鄒衡. “Guanyu tansuo Xia wenhua de tujing 關於探索夏文化的途徑 [Concerning the Path toward an Investigation of Xia Culture]." Henan wenbo tongxun 河南文博通訊, no. 1 (1978): 34-36.

Zou Heng 鄒衡. Xia Shang Zhou kaoguxue lunwen ji 夏商周考古學論文集 [Collected Writings on the Archaeology of the Xia, Shang, and Zhou Dynasties]. Beijing: Wenwu chubanshe, 1980.

Zou Heng 鄒衡. “Xia wenhua yantao de huigu yu zhanwang 夏文化研討的回顧與展望 [Research into Xia Culture: Retrospect and Prospects].” Zhongyuan wenwu 中原文 物, no. 2 (1990): 3-14.

Zou Heng 鄒衡. Xia Shang Zhou kaoguxue lunwen ji (xuji) 夏商周考古學論文集 (續集) [Collected Writings on the Archaeology of the Xia, Shang, and Zhou Dynasties (Supplementary Volume)]. Beijing: Kexue chubanshe, 1998. 